\title{
Narrative Style: A Sociolinguistic Analysis of Oral Personal Experience Narratives
}

\author{
* Dr. Liaqat Iqbal, Assistant Professor \\ ** Dr. Ayaz Ahmad, Lecturer \\ *** Mr. Irfan Ullah, Assistant Professor
}

\begin{abstract}
Personal narrative, a very important subgenre of narratives, is usually developed in a particular style. To know its specificity, in this study, oral personal narratives have been analyzed. For this purpose, twenty oral narratives, collected from twenty students of BS English, have been analyzed. In order to understand the macrostructure, i.e., narrative categories, Labov's (1972) model of sociolinguist features of narratives has been used. For the analysis of microstructures, Halliday and Hasan's (1976) five key cohesive ties: references, conjunction, substitution, ellipses, and lexical ties have been used. It was found that with little variations, most of the personal experience oral narratives follow the Labov's structure of narrative analysis, i.e., abstract, orientation, complicating actions, resolution, evaluation, and coda. Likewise, while doing microanalysis, it was found that the narratives were well-compact with the help of elements of cohesive ties. The study shows that oral personal experience narratives can have the same structure as that of written narratives.
\end{abstract}

Keywords: Personal narratives, Labov's model, Sociolinguistic analysis, Cohesive ties

\section{Introduction}

Generally speaking, a narrative is a story that consists of events and sequences. A narrative is any story where past experiences are recollected, where the occurring of events is presented with the help of a verbal sequence of clauses (Labov, 1972). These clauses are usually brought in temporal sequence. Narratives can be as short as a few clauses or as long as a complete book. Berger (1997) says that narrative is a story already happened or happening. A narrative can be an account of the different happenings related to culture, media, history or any other field. Keeping in view its multidisciplinary nature, narrative analysis can include "biography, autobiography, life history, oral history, autoethnography, life narrative and the sociology of storytelling" (Earthy \& Cronin, 2008, p. 421). A narrative usually consists of two parts: story and discourse that represent a story (Carvalho, 2000). A narrative is an important aspect of human life that is present in many spheres. It is believed that who we are and what we think is usually made known to us by the narratives, we tell regarding ourselves. It means that everyone has some narratives, and she/he has the right to narrate (Bamberg, 2010). We seek the healing effects of narratives by looking at our selfhood in narratives and we meet our self-realization when we listen to our narratives. It highlights the problems and sufferings which were not awake (Illouz, 2008). According to Randall (1995), narratives encapsulate our experiences and reflect what we are. Regarding the importance of narratives, Franzosi (1998) quotes Barthes, who says:

Narrative is present in myth, legend, fable, tale, novella, epic, history, tragedy, drama, comedy, mime, painting (think of Carpaccio's Saint Ursula), stained glass window, cinema, comics, news items, conversations. Moreover, under this almost infinite diversity of forms, narrative is present in every age, in every place, in every society; it begins with the very history of mankind and there nowhere is nor has been a people without narrative. All classes, all human groups, have their narratives...narrative is international, transhistorical, transcultural: it is simply there, like life itself...

(Barthes, 1977, p. 23)

This quote not only shows that narratives are vital and imperative but also universal. Keeping its universality and importance in mind, different authors have talked about its structure and different constraints; however, the most influential of these which is also the focus of this study is Labov's (1972) model of narrative analysis.

\footnotetext{
* Department of English, Abdul Wali Khan University, Mardan Email: liaqat@awkum.edu.pk

** Department of English, Abdul Wali Khan University, Mardan Email: ayazahmad@awkum.edu.pk

*** Department of English, Abdul Wali Khan University, Mardan Email: irfanullah@awkum.edu.pk
} 


\section{Objectives of the Study}

The objectives of the study are:

1. To find out the organizational style of oral personal experience narratives of the university students.

2. To explore how the oral personal experience narratives of the university students are connected through cohesive ties.

\section{Research Questions}

1. What organizational style do oral personal experience narratives of university students follow?

2. How are the oral personal experience narratives of the university students connected through cohesive ties?

\section{Methodology}

For this study, 20 students of BS level from the Department of English, Abdul Wali Khan University, were randomly selected to record their personal narratives. They were asked to narrate any personal narrative which they consider worth sharing. They were also ensured that their identity will not be disclosed. In this way, they were made confident that whatever they share, they will not be held responsible for and the narrative will be only used for research purposes. Afterward, the narratives were recorded and subsequently, transcribed following van Dijk's (1997) transcription key, given below:

- $\quad$ Parenthesis enclosing $\mathrm{x}$ is used for the hesitation of the speaker, e.g. I (x), I did this.

- Capital letters indicate stress on the word or part of the word, e.g. I was advised to go there and to teach her MATHematics.

- The number of periods used shows the length of the pause between the words spoken; the greater the number of periods used, the longer the pause, e.g. and so . she asked me... that why are you so nervous.

- $\quad$ Single parenthesis enclosing word indicates that something was heard but the transcriber is not sure about the word, e.g. (word)

- $\quad$ Double parenthesis indicates not transcribed words, e.g. ((slowly))

- $\quad$ Colon shows that the immediately previous syllable is prolonged, e.g. we::ll

- The hyphen indicates the cutting short of the immediately prior syllable, e.g. But-

After transcribing the recorded narratives, all the stories were coded. The coding was done in two phases. In the first phase, all the narratives were coded according to Labov's structure that consists of an abstract, orientation, complicating action, evaluation, resolution, and coda. In the second phase, all the narratives were coded for different cohesive ties. As there were many cohesive ties, which is why only the different uses of these cohesive ties have been explored.

\section{Labov Model of Narrative Analysis}

According to Labov (1972), narratives share some basic elements. The first of these elements is abstract, which gives an introduction of the narrative and after reading that statement, one gets the basic theme of the narrative. In this way, while getting the necessary information, the listeners/readers are alerted. The second element is an orientation where the listeners/readers are oriented about the story, its setting, characters and time and the actions are usually presented in past progressive tense (Afsar, 2006). The third element of a narrative is complicating a action where actions are made complicated in the sense that the main problem is introduced to listeners with the help of past simple tense. In this way, not only the events are described with the help of descriptive clauses but also the narration is continued. In a resolution, which is the fourth element of narrative, the tension which reaches the climax in the complicating actions, starts unpacking and in this way, the tension is released. The listeners reach the conclusion of the narrative that what comes in the fats of different characters. In the fifth part, evaluation, the worth of the narrative in terms of its significance is evaluated with the help of models and other evaluative statements. In the last part, coda, the narrative comes to an end and the audience is taken back where the story started.

\section{Results and Discussions}

This section is divided into two parts: macroanalysis and microanalysis. While following the six elements of Labov's model, first of all, the narratives have been analyzed. Furthermore, as said 
earlier, twenty oral narratives were analyzed; however, in this section we have taken relevant examples from only one narrative where all of the elements of narrative were present.

\section{Macroanalysis}

\section{Abstract}

An abstract usually summarizes a story in a line or two and makes the audience aware of the basic theme. After analyzing the oral narratives, it was found that 13 narratives got abstract. For example, one of the stories, also given below, starts with "The story I have to narrate is that why I am in this position and not that and why I am so." This sentence gives an overview of what the narrative is going to be about.

\section{Orientation}

Orientation, which gives information about the characters, the place where the characters are taking parts in their activities, and the time of their actions, was found in 16 of the narratives. It was said in one of the narratives, "Some years ago, when I was in class eight, I fell in love with one of my relative[s]". In this line, information about the character "I", i.e., the narrator of the story; time "some years ago when I was in class eight", and also about the action, that is, falling in love "I fell in love" with the other character "my relative" are given. The narrative has the character, time, action, and setting. In this way, through character, time and action, the setting has been created and the different aspects of the narrative have been introduced.

\section{Complicating Action}

Complicating action often starts with narrative clauses where the information about the different happenings is given. This element of the narrative is a compulsory part of any story and that is why, in all the twenty narratives, this element was found. All the narratives got some sort of climax. But quite differently, the complicating action in the narrative wherefrom examples are quoted here, is more complicated, which is rather embedded in the orientation. The orientation starts from "Some years ago when I was in class eight, I fell in love with one of my relative[s]" where we can find both orientation as well as a first narrative clause which kicks off the complicating action. In both cases, the verb of the narrative clause is the simple past and continues until the evaluation of the stories.

\section{Resolution}

The resolution, as the name suggests, is that part of a narrative where the result of the complicating action is shown. In this way, the tension that is built in the complicating action is released. In the selected narrative, the narrator says "In my matriCULATion as we were both in this complex that one of both...will express herself..she is too expecting that ((very slowly)) that. We both missed that". Here, the climax of falling in love stops and tension is released by saying that "we both missed that". Both the lovers while waiting for each other's response miss the opportunity of love.

\section{Evaluation}

Evaluation is that part of a story where the audience is made aware of the narrative's importance in terms of the emotional side. Evaluation usually consists of comments from the narrator. It is said by the narrator in the narrative that "I will come to this conclusion..that why one..fall in love...and what to do in these circumstances..that whether one should love or not". The narrator has actually presented the consequences of falling in love and its negative effects in case of failure.

\section{Coda}

Coda, being the optional part, was only found in three of the twenty narratives. In one of the narratives, which was about the life failures of the narrator, the audience is brought back to the point where they entered by saying "and that is how I started my struggle."

One of the narratives with labeled elements of Labov's structure of narrative is shown below:

\section{Table 1}

Labov's Structure of Narrative Analysis in the Selected Narratives

\begin{tabular}{|c|c|}
\hline $\begin{array}{l}\text { Labovian } \\
\text { Category }\end{array}$ & Narrative \\
\hline Abstract & $\begin{array}{l}\text { The story I have to narrate is that why I am in this position and not in that and why I am } \\
\text { so. }\end{array}$ \\
\hline Orientation & $\begin{array}{l}\text { Some years ago, when I was in class eight, I fell in love with one of my relative[s]. At } \\
\text { that time, I was in my class eight. I was advised to go there and to teach her } \\
\text { MATHematics. After teaching, when I was coming back home, I glanced at her and I.. } \\
\text { fell in love. So, I came my home. I was feeling..I was feeling like I am missing }\end{array}$ \\
\hline
\end{tabular}




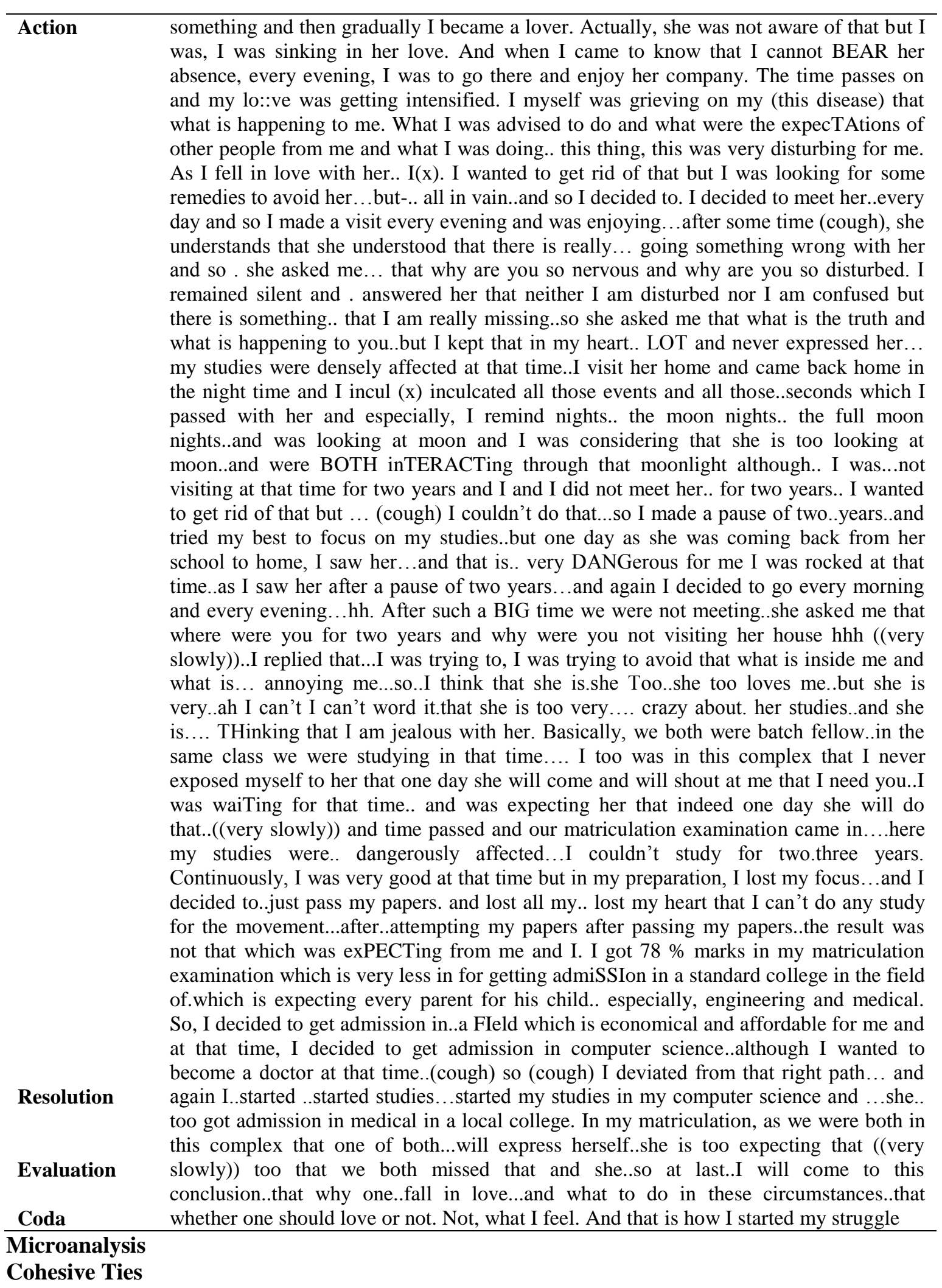

In carrying out microanalysis, as said earlier, Halliday's and Hasan's (1976) five key cohesive ties: references, conjunction, substitution, ellipses, and lexical ties were employed. As narrative is a complete whole with many basic elements, cohesive ties help this whole to be more compact and organized. Through cohesive ties, the different parts of the narrative are made more connected. In fact, cohesive ties are the elements that create semantic clarity of a text. In this study, the range of different possibilities of meaning in the selected narratives has not been discussed, yet the use of 
different possibilities of cohesive ties has been shown. These cohesive ties are discussed as the following:

\section{Reference}

There are many pronouns, e.g., personal, reflective, interrogative, and demonstrative that are used for referencing. These references can either take the form of anaphoric referencing or cataphoric referencing. In the narratives, the personal reference with personal pronoun $I$ comes in the category of anaphoric references because $I$ refers back to the narrator of the story. Similarly, the second example from the oral narrative got the form of the demonstrative pronoun as this which refers forward to thing and hence, it is a cataphoric reference. It is another issue that "thing" in the spoken form of the story refers back to the people's expectations and that is why in this case, it comes in the category of anaphoric references. This third example in both the narrative shows the presence of relative pronouns who and which, that refer back to the field in the spoken form which is an anaphoric reference because of its back reference. Likewise, if the fourth example in the given narrative is considered, it is understood that "here" is a demonstrative pronoun. "Here" is a temporal pronoun that refers to the particular time when the narrator studies were dangerously affected. Illustrations from the narrative are given in table 2.

Table 2

Use of References in the Oral Narratives

Microanalysis category Example/s from oral personal experience narrative

References $\quad 1 . \quad I$ fell in love with one of my relative[s].

2. This thing was very disturbing for me.

3. I decided to get admission in..a FIeld which is ecno.economical and affordable for me.

4. Here my studies were.. dangerously affected

\section{Conjunctions}

Conjunctions can work as coordination or subordination depending on their different uses. That is why they are used for linking. In the selected narratives, many examples show this linkage. The first example in both the narratives is "and". This is a coordinating conjunction because it takes part in coordinating different parts of a sentence as shown in Table 3. Conversely, "so" is a causal conjunction. Equally, in the fifth sentence, we got two conjunctions "not" and "nor" giving the same meaning as that of "neither and nor". What happens here is "neither" is substituted by "not" because of the informality of the spoken language yet the meaning is the same. This type of conjunction set is called correlative conjunctions.

Table 3

Use of Conjunctions in the Oral Narrative

\begin{tabular}{|c|c|}
\hline Microanalysis category & Example/s from oral personal experience narrative \\
\hline Conjunctions & $\begin{array}{l}\text { 1. I was advised to go there and to teach her MATHematics. } \\
\text { 2. I.. fell in love. so I came my home. } \\
\text { 3. I was feeling like that I am missing something. } \\
\text { 4. Actually, she was not aware of that but I was I was sinking in her love. } \\
\text { 5. I remained silent and . answered her. that not I am disturbed nor I am } \\
\text { confused. }\end{array}$ \\
\hline
\end{tabular}

\section{Substitution}

According to Halliday and Hassan (1976), substitution is the category in which one thing is substituted by another. Such words are substituted by other words. It is said, "I myself was grieving on my (this disease)." In this example, "love" is substituted by "this disease".

Table 4

Use of Substitution in the Oral Narrative

\begin{tabular}{ll}
\hline Microanalysis category & Example/s from oral personal experience narrative \\
\hline Substitution & My love was getting intensified. I myself was grieving on my (this disease). \\
\hline
\end{tabular}

\section{Ellipses}

In this situation, usually words or parts of a sentence are omitted and the meaning is made clear from the context. In the narratives, there were few examples where elliptical use of language was done. In the last of the narrative, as the narrator is too much pessimistic about love, he asks a question "I will 
come to this conclusion..that why one..fall in love...and what to do in these circumstances..that whether one should love or not?". He answers himself "Not, what I feel." In this example, instead of repeating the sentence "one should not fall in love", the narrator simply says "not" which means "one should not fall in love".

Table 5

Use of Ellipses in the Oral Narrative

Microanalysis category Example/s from oral personal experience narrative

\begin{tabular}{ll}
\hline Ellipsis & $\begin{array}{l}\text { I will come to this conclusion..that why one..fall in love...and what to do } \\
\text { in these circumstances..that whether one should love or not?” Not, what I } \\
\text { feel }\end{array}$ \\
\hline
\end{tabular}

\section{Lexical Ties}

In this type of cohesive tie, the meaning and cohesion therein are strengthened with the help of the repetition of words or by using synonymous words (Hatch, 1992). In the selected narrative, there are examples in which the repetition of words or the use of synonymous words was observed. "Love" in example 1 and 2 and "moon" in example 4 from the oral narrative indicate the repetition of words. However, in the spoken story, love is first referred to as love but in the next sentence, it has been called by the name of this disease.

Table 6

Use of Lexical Tie in the Oral Narrative

Microanalysis category Example/s from oral personal experience narrative

Lexical ties $\quad 1$. I fell in love with one of my relative[s].

2. My love was getting intensified.

3. I myself was grieving on my (this disease).

4. And was looking at moon and I was considering that she is too looking at moon.

\section{Conclusion}

Narratives play an important role in one's life. A narrative can add to history, culture, and biographies. Narrative analysis not only helps in determining macrostructure of a narrative, it also plays an important role in the microstructure. The analysis which is based on Labov's model of narrative analysis that was developed long ago in a different culture shows that narratives usually have the same macrostructure in different cultures and eras. However, there can be a difference in the occurrence of elements of the macrostructure as evident from the data analyzed. It means that it is not necessary that a narrative should always start from an abstract. There were few stories which started from orientation. Overall, it can be said that there is usually a set pattern of the different elements of a narrative with the minimum variation. Further, as this study was based on spoken data, the future researches should work compare spoken narratives with written narratives and show the possible difference between these two modes of the genre.

\section{References}

Afsar, A. (2006). A discourse and linguistic approach to Biblical and Quranic Narrative. Islamic Studies, 45 (4), pp. 493-517.

Berger, A. (1997). Narratives in popular culture, media and everyday life. London: Sage Publications. Bamberg, M. (2010). Who am I? Narration and its contribution for self and identity. Theory \& Psychology, 21 (1), 1-22.

Carvalho, A. (2000). Discourse analysis and media texts: A critical reading of analytical tools, paper presented at the 'International Conference on Logic and Methodology', RC 33 meeting (International Sociology Association), Köln, 3-6

Earthy, S. \& Cronin, A. (2008). Narrative analysis. In N. Gilbert (Ed), Researching Social Life, 3rd Edition, London: Sage (pp. 420-439).

Franzosi, R. (1998). Narrative analysis-or why (and how) sociologists should be interested in narrative author(s): Annual Review of Sociology, 24, 517-554, retrieved May 15, 2019 from www.jstor.org

Halliday, M. \& Hasan, R. (1976). Cohesion in English. London: Longman.

Hatch, E. (1992). Discourse and language education. New York: Cambridge University Press. 
Illouz, E. (2008). Saving the modern soul: Therapy, emotions, and the culture of self-help. Berkeley, CA: University of California Press.

Labov, W. (1972). Language in the inner city. Philadelphia: The University of Pennsylvania Press.

Randall, W. L. (1995). The stories we are: An essay on self-creation. Toronto, Canada: University of Toronto Press.

Van Dijk. T. (1997). Discourse as social interaction. Honton: Sage Publications. 